\title{
Study on the sediment consolidation process under different salinity fields in the Yellow River Estuary
}

\author{
Chuanfang Xiong ${ }^{1, a}$, Hongxian Shan ${ }^{1, b}$, Shaotong Zhang ${ }^{1, c}$, Chaoqi Zhu ${ }^{1, d}$ \\ and Yonggang $\mathrm{Jia}^{2, \mathrm{e}}$
${ }^{1}$ Shandong Provincial Key Laboratory of Marine Environment and Geological Engineering, Ocean University of China, Qingdao 266100, China \\ 'Laboratory for Marine Geology, Qingdao National Laboratory for Marine Science and Technology, \\ Qingdao 266061, China \\ a1004892001@qq.com, bhongxian@ouc.edu.cn, 'shaotongzhang@qq.com, \\ 'george-zhu@foxmail.com, eyonggang@ouc.edu.cn
}

\begin{abstract}
Keywords: sediments; salinity field; consolidation; Yellow River Estuary
Abstract. A field experiment was carried out on an intertidal flat of the Yellow River delta to study the consolidation process of sediments under different salinity fields. Three test pits were excavated to simulate newly deposited seabed by backfilling well-mixed sediments with water in different salinities. Wave parameters and pore water pressure evolutions throughout the consolidation process were recorded. Results were listed as follows: during the rapid consolidation stage, salinity has a promoting effect on the increase of consolidation degree. While during the normal consolidation stage, there is an optimal salinity value to make the consolidation degree the highest.
\end{abstract}

\section{Introduction}

The environment of estuary area is complex, in which the freshwater and the saline water flow together, causing a lot of natural disasters ${ }^{[1]}$. The Yellow River is famous for its high fluvial sediment content. Every year a huge amount of sediment were carried into areas with the weak tidal, $80 \%$ of which rapidly deposited in the estuarine delta area ${ }^{[2]}$. The dynamic behaviors of estuarine area are being studied. Liu et al. ${ }^{[3]}$ found that the physical and mechanical properties in the process of the soil consolidation can be measured by the electrical resistivity monitoring, but the method is still in the research stage. Meng et al. ${ }^{[4]}$ and Jia et al. ${ }^{[5]}$ investigated the erodibility and geotechnical strength of intertidal sediments in Yellow River Delta. And Jia et al. ${ }^{[6]}$ monitored the accumulation and dissipation of the pore water pressure with different wave heights through the indoor flume experiment, which can clarify the mechanism of wave-induced seabed re-suspension and liquefaction in the Yellow River estuary.

The ever-changing salinity field in the Yellow River estuary will affect the dynamic behavior of the sediment into the sea. This study focuses on the accumulation and dissipation of pore water pressure in the sediments with different salinities throughout the in-situ consolidation test on an intertidal flat of the Yellow River estuary. This paper is trying to quantitatively describe the relationship between salinity and sediments consolidation process via in-situ measurement of pore water pressure and educe its impact mechanism.

\section{Materials and methods}

The Yellow River runs into Bohai Sea in the northern part of Shandong province, bringing a large number of fresh water, sediments and biogenic materials every year. A test point is chosen on an intertidal flat $\left(37^{\circ} 52^{\prime} 46^{\prime \prime} \mathrm{N}, 119^{\circ} 04^{\prime} 31^{\prime \prime} \mathrm{E}\right)$, which is in the northern part of the Yellow River Delta formed during 1964 to 1976. (Fig. 1)

A consolidation experiment in sedimentary environments of different salinities was conducted in the above study area during $12^{\text {th }}$ to $17^{\text {th }}$ in September 2014. To simulate the natural consolidation process in different salinities, sediments which contain different salinities are produced. The test 
water is produced by mixing different volume ratios of the seawater and the freshwater. The mixing ratio and salinitiy of the test water are presented in Table 1 . Three test pits $(60 \mathrm{~cm} \times 60 \mathrm{~cm} \times 60 \mathrm{~cm})$ were excavated on the tide flat, which were parallel to the coastline. Mix three kinds of test water with soils until forming a uniform flowing mud. Then put the mud into three test pits which were named A, B and C. The pore water pressure measuring device is showed in Fig. 1. In the process of backfilling, three pore water pressure probes were buried in the same $30 \mathrm{~cm}$ depth of each test pit to monitor the values of pore water pressure continuously. An automatic and dynamic wave and tide recorder (Fig. 1) was installed in the vicinity of the test points.

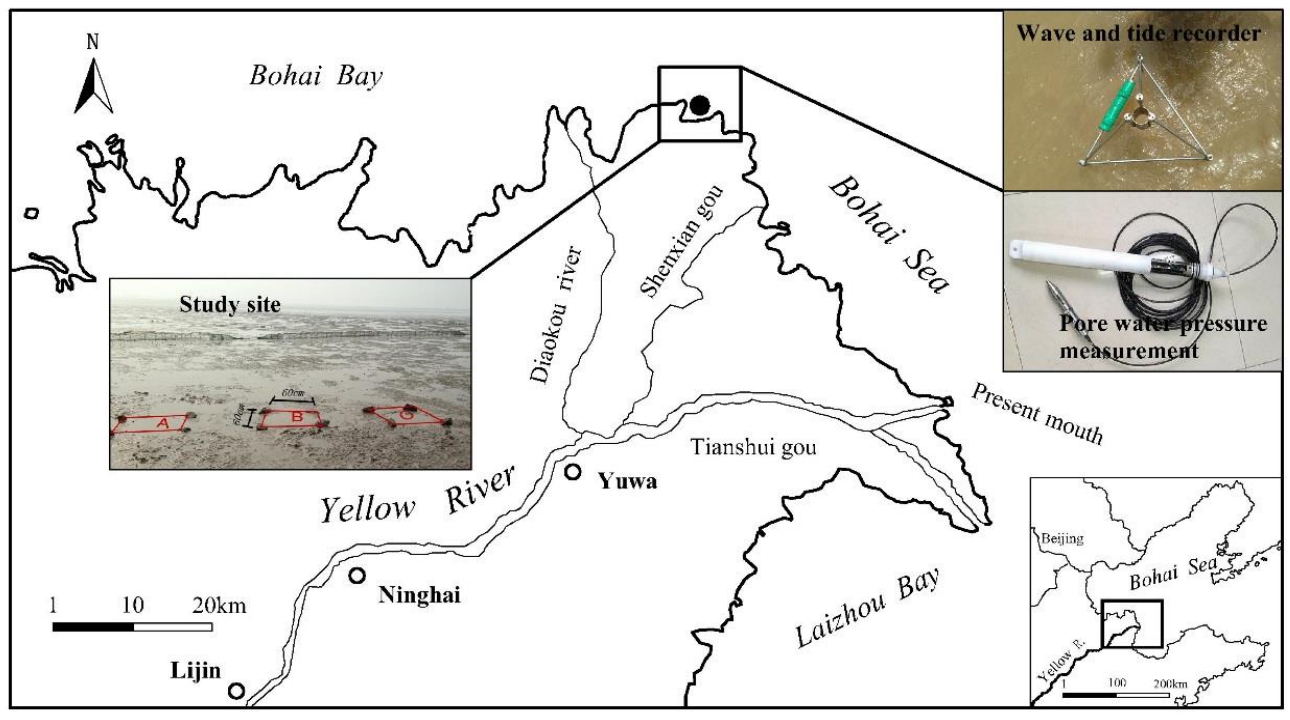

Fig.1. The location of testing areas and the measurements

Table 1 Sedimentary environments of different salinities in the experiment

\begin{tabular}{cccc}
\hline Number of test pits & A & B & C \\
\hline Mixing ratio & 100\% freshwater & 50\% seawater and 50\% freshwater & $100 \%$ seawater \\
Salinity of test water/\%o & 1.85 & 24.67 & 31.3 \\
\hline
\end{tabular}

\section{Results}

After the calculation of excess pore water pressure, time series in different salinities are given in Fig.2. The change of excess pore water pressure had a periodicity with nearly 24 hours a cycle time. Set each cycle to a period. Five consolidation periods are produced during the testing time. The consolidation processes in three test pits were roughly the same, divided into two stages. The first stage is called rapid consolidation stage which is comprised of consolidation period I and II. It appeared at 18 $o^{\prime}$ clock September $12^{\text {nd }}$ to 18 o'clock September $14^{\text {th }}$. The second is the stage of normal consolidation

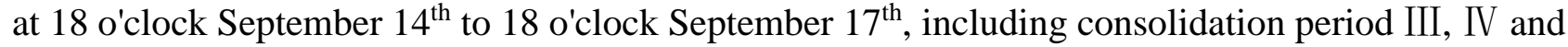
$\mathrm{V}$. In the consolidation period I after backfilling, with the salinity of each test pit increased, the cumulative values of excess water pressure became smaller. The maximum cumulative value of excess pore water pressure in test pit $\mathrm{A}$ was $0.50 \mathrm{kPa}$, in test pit $\mathrm{B}$ was $0.36 \mathrm{kPa}$, and test pit $\mathrm{C}$ was $0.25 \mathrm{kPa}$. But they dissipated on different degrees subsequently. In the consolidation period II, the change of the three curves was approximately the same, with the maximum reached $0.49 \mathrm{kPa}$. It turned to the normal consolidation stage when the excess pore water pressure caused by self-weight consolidation was completely dissipated. As we can see in the consolidation period III, IV, and V, the excess pore water pressure had obvious accumulation and dissipation, forming an overall upward change ultimately. And the amplitudes rise and fall were basically the same. But the relative values have been maintained always the same, test pit $\mathrm{C}>$ test pit $\mathrm{A}>$ test pit $\mathrm{B}$.

There were two big waves in the test, respectively at 19:30 September $14^{\text {nd }}$ and 7:30 September $15^{\text {nd }}$. The maximum wave height reached $1.17 \mathrm{~m}$ and $0.57 \mathrm{~m}$. Hence, the pore water pressure response 
in different salinities before and after the big waves was analyzed. It was shown that, only the test pit $\mathrm{C}$ responded to big waves, leading to a sharp increase with a slightly time lag. Test pit $\mathrm{B}$ which has a lower concentration of salt and test pit A with the lowest salinity had no accumulation, which shows that the low salinity has no response to the big waves.

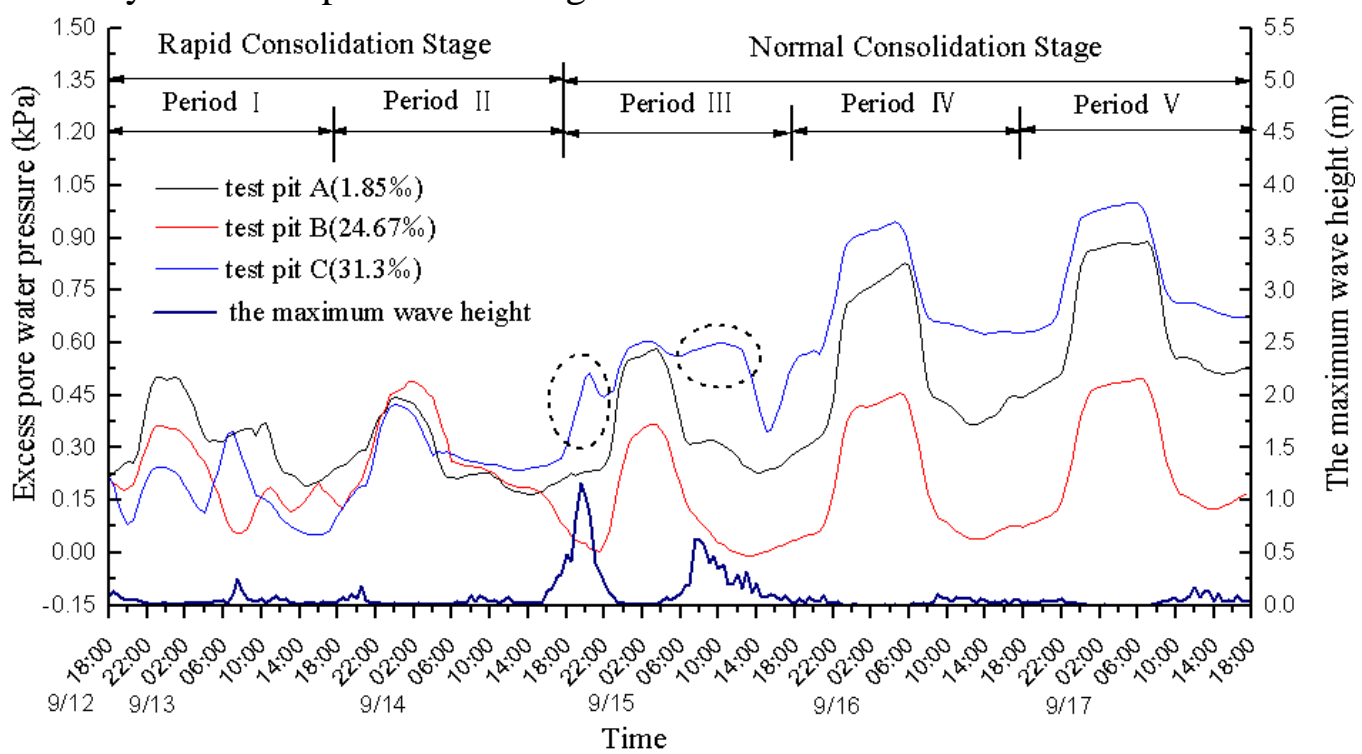

Fig. 2. Time series of excess pore water pressure during consolidation

\section{Discussion}

Excess pore water pressure value was averaged in every 24 hours to characterize the changes of each consolidation period in the process of consolidation. According to Eq. (1) ${ }^{[7]}$, the averaged excess pore water pressure of each consolidation period was transformed into the averaged degree of consolidation correspondingly to illustrate the average degree of dissipation of excess pore pressure obviously in the whole process of consolidation.

$$
U=\frac{\sigma \prime}{\sigma}=1-\frac{u}{\sigma}
$$

$U$ is the average degree of consolidation; $\sigma^{\prime}$ is the effective stress values, the pore pressure sensor buried in the depth of $3 \mathrm{~cm}$ as motioned above; and $u$ is the averaged excess pore water pressure values.

The effect of salinity on degree of consolidation is different on two consolidation stages as Fig.3 and Fig. 4 showed. In period I , with the increase of salinity, consolidation degree increases and has a good linear relation which is a $0.2 \%$ increase in sediment consolidation degree for every $1 \%$ sea water salinity increase. And in period II, the effect of salinity on the consolidation process is not obvious, with almost a horizontal line. Therefore, on rapid consolidation stage, salinity generally has a promoting effect on the consolidation process (Fig. 3). But the consolidation degree in every period of normal consolidation stage first increases then decreases with the increase of the salt content during the consolidation process. (Fig. 4) It is worth noting that, on the normal consolidation stage, there is an optimal intermediate salinity value (around 24\%o). Below it, the salinity will promote the process of consolidation. Over it, the inhibitory effect will be produced with the increase of salinity. And the best promotion time is the consolidation period III.

According to the diffuse double layer theory, an increase in pore fluid salinity causes a decrease of diffuse double layer thickness and consequently an increase of attractive forces between fine particles ${ }^{[8]}$, finally increases the consolidation degrees on the early stage of consolidation. But as the salinity continues to increase, more valence cations rush into the adsorption layer to make the particle charge reversal. And it is possible to make a higher surface potential and cause a decrease of repulsive forces between fine particles. This kind of "exclusive effect " always occurs when the salinity is too high, and eventually influences the consolidation process. 


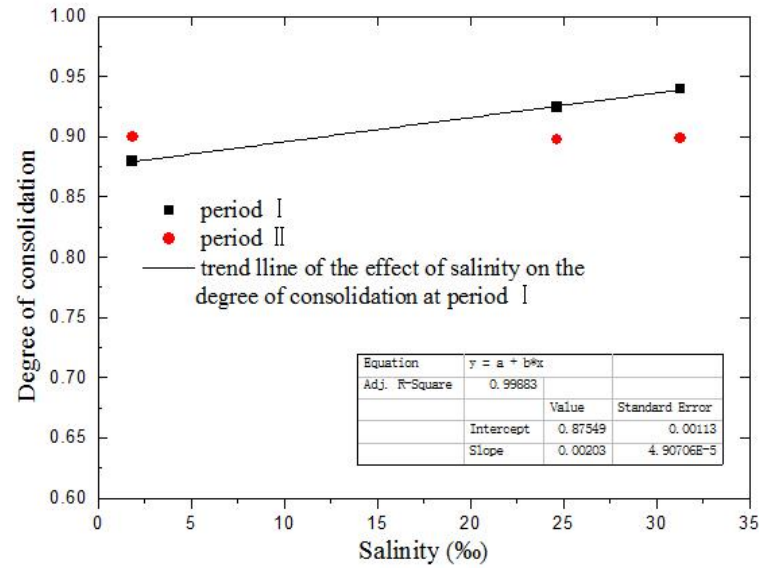

Fig. 3. The relationship between salinity and consolidation degree on rapid consolidation stage

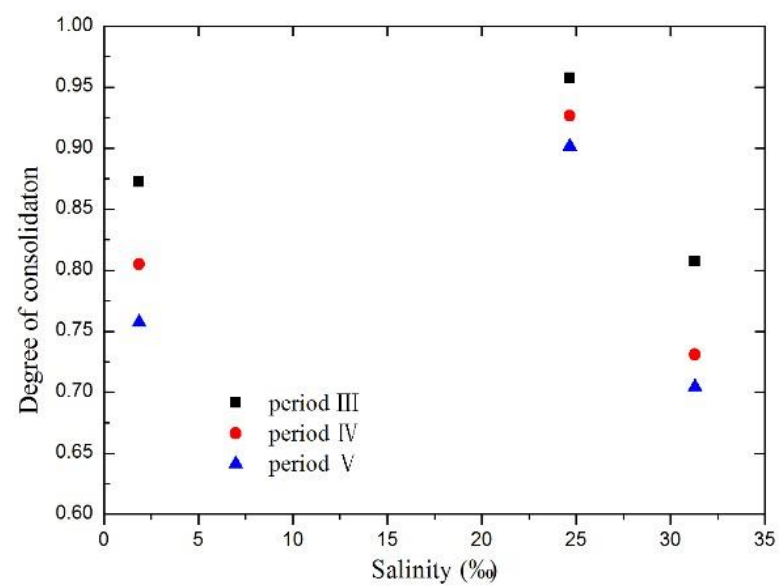

Fig. 4. The relationship between salinity and consolidation degree on normal consolidation stage

\section{Conclusions}

Based on the effect of salinity on consolidation, the consolidation process is divided into the rapid consolidation stage and the normal consolidation stage. 1) On the early stage of rapid consolidation, salinity has a promoting effect. And it is a good linear relation between salinity and consolidation degree, which is a $0.2 \%$ increase in consolidation degree for every $1 \%$ o sea water salinity increase. 2 ) On the normal consolidation stage, there is an optimal salinity value. The salinity will take a promoting effect when below it. An inhibitory effect will be produced as the salinity increase when over it. And the best promotion time is the period III.

\section{Acknowledgements}

This study was funded by the National Natural Science Foundation of China (contract No. 41372287).

\section{References}

[1] Jia, Y. G., Zhu, C. Q., Liu, L. P., \& Wang, D.. (2016). Acta Geologica Sinica (English Edition), 90(4): 1455 1470.

[2] Saito, Y., Yang, Z. S., \& Hori, K. (2001). Geomorphology, 41(2-3), 219-231.

[3] Liu, X. L., Jia, Y. G., Zheng, J. W., Shan, H. X., \& Li, H. L. (2013). Engineering Geology, 164, 77-85.

[4] Meng, X. M., Jia, Y. G., Shan, H. X., Yang, Z. N., \& Zheng, J. W. (2012). International Journal of Sediment Research, 27(2), 240-249.

[5] Jia, Y. G., Liu, X. L., Shan, H. X., Zheng, J. W., \& Huo, S. X. (2011). International Journal of Sediment Research, 26(3), 318-330.

[6] Jia, Y. G., Zhang, L. P., Zheng, J. W., Liu, X. L., Jeng, D. S., \& Shan, H. X. (2014). Ocean Engineering, 89, 146-156.

[7] Chen, N. Y., Meng, Q. S., Ma, L., \& Hao, L. L. (2014). Geotechnical Investigation \& Surveying, 42(9),11-16. (in chinese)

[8] Virtasalo, J. J., Ryabchuk, D., Kotilainen, A. T., Zhamoida, V., Grigoriev, A., Sivkov, V., \& Dorokhova, E. (2014). Marine Geology, 350, 84-96. 